\title{
Effects of scallop dredging on temperate reef fauna
}

\author{
H. Hinz*, D. Tarrant, A. Ridgeway, M. J. Kaiser, J. G. Hiddink \\ School of Ocean Sciences, University of Wales-Bangor, Menai Bridge, Anglesey LL59 5AB, UK
}

\begin{abstract}
Scallop dredging is considered to be one of the most destructive bottom fisheries, yet empirical field evidence to support this assertion, in particular for highly structured habitats, is limited. With this study, we investigated the effects of scallop dredging on the fauna of a temperate stony reef through a comparison of areas subject to different levels of fishing activity. Significant negative effects of scallop dredging were evident for 3 of the 9 species analyzed from video samples. Sessile emergent epifaunal species had significantly lower occurrences and abundances at fished sites compared to unfished sites, while commercial target species such as scallops and crabs were not significantly affected by fishing. Contrary to expectation, the pink sea fan Eunicella verrucosa, a species of local conservation concern, did not show a significant negative response with respect to abundance and average body size to the intensity of scallop dredging it had been subjected to. The absence of a clearly detectable fishing effect on this species may be related to its association with the topographically more complex areas of the reef in which the fishing efficiency of scallop dredges will be reduced. The evidence presented here demonstrates that not all species were equally affected by scallop dredging and that the complexity of stony reef habitats may provide some measure of protection at low fishing intensities.
\end{abstract}

KEY WORDS: Eunicella verrucosa - Dredging - Emergent epifauna - Fisheries management · Fishing impacts $\cdot$ Marine protected areas $\cdot$ Rocky reef $\cdot$ Scallop

\section{INTRODUCTION}

With the overexploitation of many demersal fish stocks, fishers have moved increasingly from targeting traditional finfish species to alternative target species such as shellfish (Pauly et al. 1998). Between 1994 and 2009 , UK landings of scallops increased by $58 \%$ from 14 to 34 thousand tonnes, while for the same period, landing of cod and haddock deceased by 67 and $61 \%$, respectively (Marine Management Organisation 2009). While this increase in UK scallop landings is related to an increase in the number of vessels participating in this fishery following the decline of major white fish stocks, there has been a recent upward trend in scallop recruitment that may be climate related (Shephard et al. 2010). In Northern Europe, scallops are a non-quota species that have a high consumer demand and hence a high economical value. The latter means that harvesting scallops with dredges is more profitable than harvesting demersal fish species using otter or beam trawls (Abernethy et al. 2010).
Within UK waters and elsewhere, increased fishing effort from scallop dredging has led to concerns over the status of local stocks and the ecological impacts of this activity on associated habitats and communities (Hall-Spencer \& Moore 2000, Kaiser et al. 2000, Blyth et al. 2004). Scallop dredging necessitates the use of heavy dredges that are dragged across the seabed and has been identified as one of the most damaging fishing activities in relation to benthic habitats and species (Kaiser et al. 1996, 2006, Hall-Spencer \& Moore 2000, Jenkins et al. 2001). Emergent epifauna, sessile organisms that live attached to the substratum such as sponges, erect bryozoans or anemones, are particularly likely to be impacted by scallop dredging, especially if they are long-lived, slow-growing species with fragile bodies (Guijarro Garcia et al. 2006).

Scallop fisheries in the UK target 2 species, the king scallop Pecten maximus and the queen scallop Aequipecten opercularis. Fishing activity for these species is generally restricted to well defined areas of the seabed due to habitat associations and possibly the lar- 
val supply dynamics of scallops. In general, both species of scallops co-occur on gravel or mixed substrata, but also can occur on mud and harder seabed types (Shumway \& Parsons 2006). The fauna associated with gravel and rocky habitats are known to be sensitive to bottom dredging and are likely to have prolonged recovery times $>5 \mathrm{yr}$, compared with shallow sandy seabed habitats where recovery can occur in $<1 \mathrm{yr}$ (Dernie et al. 2003, Kaiser et al. 2006). Evidence from previous studies of fishing impacts on biogenic habitats (such as maerl beds) have demonstrated significant effects of scallop dredging on epibenthic species (HallSpencer \& Moore 2000, Kaiser et al. 2006). However, to date, no studies have examined the effects of scallop dredging on temperate rocky reefs. Moreover, while there is considerable conservation concern regarding the sensitivity of reef fauna in relation to fishing disturbance, there remains little empirical evidence that would inform quantitative predications regarding the effects of fishing disturbance on such habitats.

The present study investigated the direct effects of a scallop dredge fishery on a temperate reef habitat off the south west coast of the UK (Lyme Bay, Dorset). The reef is associated with several species of conservation concern, in particular the pink sea fan Eunicella verrucosa. In the present study we investigated the effects of scallop dredging by a local fishing fleet on epibenthic species associated with the reef habitat. Areas that were fished and unfished were compared. Additionally the implementation of the voluntary closure of 4 areas within the reef system of Lyme Bay between Septem- ber 2006 and August 2008 provided an opportunity to evaluate the positioning of these reserves with respect to their conservation potential for selected species. Furthermore by sampling across several time periods at sites within the voluntary closures (reserves) and in adjacent areas (open to fishing), the potential recovery of species could be examined.

We sought to answer 3 separate questions: (1) What were the effects of past fishing activity on the abundance (or presence) and size of the selected epibenthic species? If species were affected by past fishing events, did fished sites exhibit significantly lower abundances of selected epibenthic species compared to non-fished sites? (2) Did the voluntarily closed areas protect an adequate proportion of the species of conservation concern? For the latter to be true, the abundance of sensitive species was expected to be significantly higher within reserve areas compared to areas beyond the boundaries of the reserves. (3) Were there any significant differences in the abundances of key species at 7 and 12 mo after the implementation of the closures that indicated recovery? Recovery is significant if higher abundances of epibenthic species are evident after 12 mo within the reserves compared to areas that remained open to fishing.

\section{MATERIALS AND METHODS}

Background information on the study area. The study area in Lyme Bay (Dorset, UK; Fig. 1) is charac-

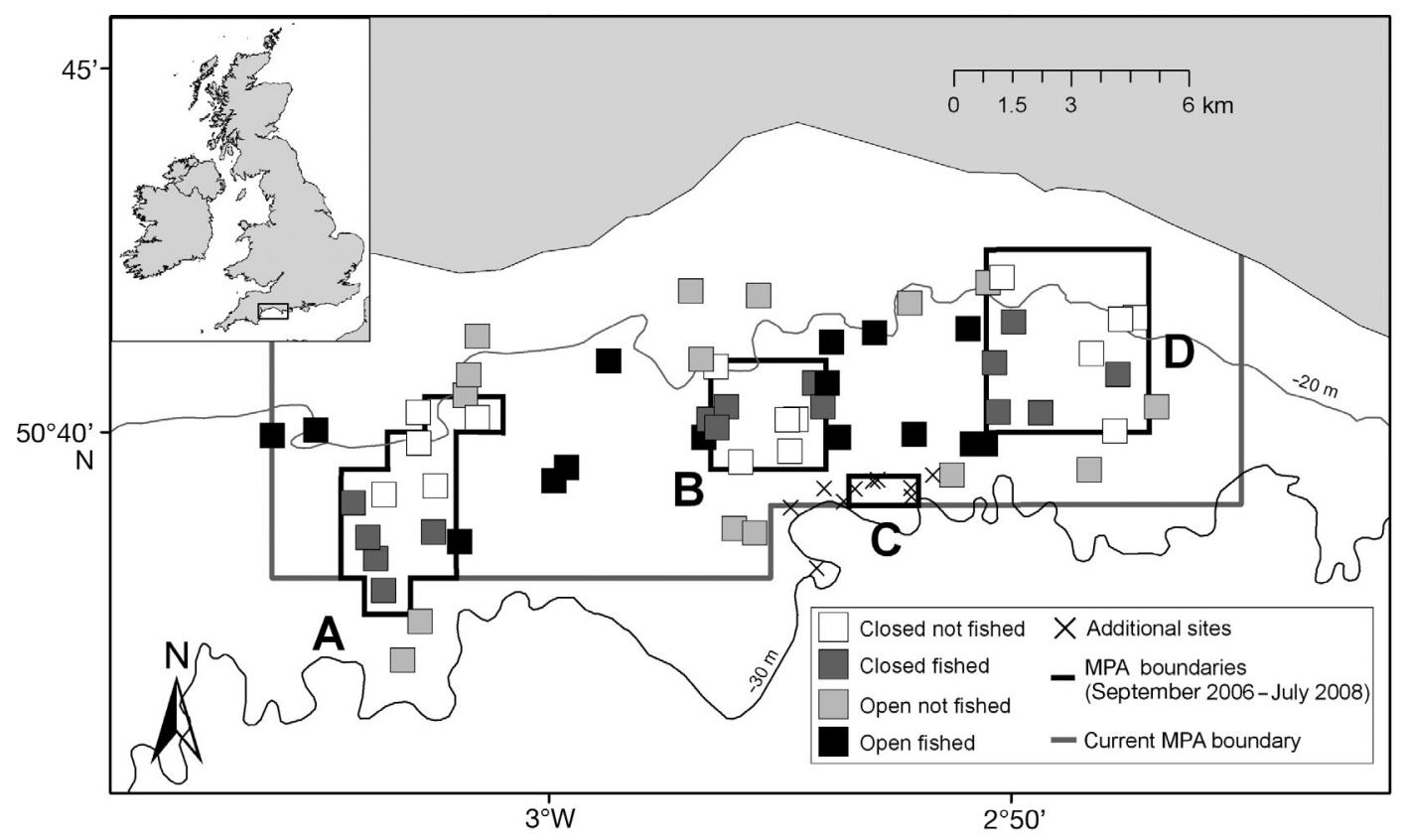

Fig. 1. Map of sampling sites resembling the experimental design adopted to monitor changes in epibenthic fauna within the marine reserve areas A, B, and D implemented between September 2006 and July 2008. Also shown is the current boundary of the reserve which came into force in August 2008. MPA = marine protected area 
terized by a limestone pavement seabed with overlaying and interspersed areas of mixed sediments. It thus represents a heterogeneous mosaic of alternating substratum types at small spatial scales. Due to the prevalence of rocky reef, this habitat complex has been identified as a temperate rocky reef under the European Communities habitat directive Annex I (Natural England 2010). The complexity of the habitat is mirrored by the diversity of emergent sessile fauna, some of which represent protected species, such as the pink sea fan Eunicella verrucosa and the sunset cup coral Leptopsammia pruvoti. Both of these species are included in the United Kingdom Biodiversity Action Plan (BAP) and are therefore considered by Natural England (UK Government statutory conservation agency) to be at risk in terms of the viability of their populations within UK waters. Other emergent epifauna of ecological significance, in terms of their contribution to habitat structure, have also been found associated with the reef, such as the bryozoan Pentapora fascialis, the soft coral Alcyonium digitatum and the erect sponge Axinella dissimilis.

In an initial attempt to achieve the conservation of this sensitive reef community and to protect a proportion of the breeding population of scallops, fishermen agreed to voluntarily concede some areas that had traditionally been fished. This resulted in the closure of 4 areas within the Lyme Bay reef area to scallop dredging in September 2006. The areas remained open for static gear fisheries that targeted crab, lobster and whelk. Static gear fishing activity increased within the closed areas following the exclusion of scallop dredging. Nevertheless, static gears are considered to have minimal direct impact on emergent epifauna (Eno et al. 2001). The identification of the 4 areas that were voluntarily closed to scallop dredging was based on the known distribution of pink sea fan Eunicella verrucosa (the primary species of conservation concern), as ascertained from a number of previous ad-hoc surveys and fishing industry knowledge. In August 2008, the 4 areas under voluntary closure were incorporated within a larger marine protected area (MPA) excluding all mobile fishing gears (Rees et al. 2010), which at that point effectively terminated our investigation into the long-term development of the 4 voluntary closed areas, comparing them with outside areas that remained open to towed fishing activities (i.e. all towed fishing activity was removed from across our study site).

Experimental design. The experimental design adopted by this study was also intended to provide the baseline from which to quantify the long-term recovery of the epibenthos within the 4 voluntary closed areas (hereafter called 'reserves') that were previously impacted by scallop dredging. For this purpose, areas both inside and outside the reserves with different past dredging regimes were identified. In other words, we located areas within the reserves that had previously been fished and also areas that had not. This exercise was repeated for areas outside the reserves. Furthermore, data from a multi-beam echo-sounder survey of the seabed was used to ensure that the selected sites were located over the reef habitat. Thus, each reserve was allocated 2 main fixed treatments both with 2 levels: (1) Protection, i.e. stations inside the reserves (Closed) and outside (Open); (2) Past Fishing Activity, i.e. stations that had been fished prior to the implementation of the reserves (Fished) and stations that had experienced no prior dredging or very low intensities prior to the implementation of the reserves (Not Fished). Each treatment had 5 replicate sampling sites that were sampled with a digital underwater video camera. Thus, the study adopted an orthogonal factorial design. Due to the small size of one of the reserves (Reserve C, see Fig. 1), not all treatment combinations could be allocated, namely areas inside the reserve that had previously been dredged could not be identified in area C. To maintain a balanced design, only the 3 larger reserves (A, B and D, see Fig. 1) were considered within the experimental design, while sites inside and outside the reserve area $\mathrm{C}$ were sampled to obtain complementary data. The reserves were not considered as a separate factor and data was analyzed in a pooled approach. We adopted this approach because the present study was primarily concerned with the effects of fishing, protection and time for the whole area rather than focusing on differences among reserves. Furthermore, the spatial independence of sampling sites outside the reserves (in relation to their association with a particular reserve) could not be assured and therefore a more appropriate approach was to pool the data.

The studied sites were sampled during 2 separate surveys, the first survey occurred at the end of March 2007, 7 mo after the implementation of the 4 voluntary reserves. The second survey was conducted 5 mo after the first survey in August 2007. Thus, the entire study spans a period of 7 and 12 mo post fishing, which is unlikely to be sufficient for full recovery of the communities associated with reefs in terms of biomass, but may be adequate to record the start of recovery in relation to the abundance of taxa or species richness.

Past fishing effort. Scallop-dredge fishers voluntarily provided high-resolution continuously recorded track plots from fishing tows conducted in the area between the years 2000 and 2006. In total, track plots from 5 boats were made available that represented $\sim 12 \%$ of the local fleet. This data provided an unprecedented resolution of fishing activity compared to vessel monitoring systems (VMS) that record at intervals of once every $2 \mathrm{~h}$ (Dinmore et al. 2003). The trawl tracks 
provided were judged by the local fishermen's association (South Western Inshore Fishermen's Association [SWIFA]) to be representative of the general effort distribution with respect to spatial coverage and relative fishing intensities. Fishing effort in this study area was expressed as the number of times a $500 \times 500 \mathrm{~m}$ area was dredged from 2000 to 2006, and was calculated within a GIS assuming a standard width of a gang of scallop dredges of $8 \mathrm{~m}$ (assumed gear configuration of $2 \times 4$ Newhaven dredges). The track plot data were cross-checked by correlating them with vessel sightings of the whole fleet collected by fisheries patrol aircraft of the UK's Marine Fisheries Agency from the same area and period. A significant correlation between the 2 datasets (Spearman's rank: $\mathrm{n}=60, \mathrm{r}_{\mathrm{S}}=$ $0.478, \mathrm{p}<0.001$ ) was found and provided independent validation that the data provided by fishermen accurately described general fishing patterns and spatial coverage. Overall, the track plot data was considered to be more precise both spatially and temporally at smaller spatial scales compared to vessel sightings by the fisheries patrol aircraft. The track plots represent continuous accurate positions of individual vessels. In contrast, fisheries patrol aircraft sightings and VMS data provide only a snapshot of vessel positions at longer time scales (twice monthly and $2 \mathrm{~h}$ intervals, respectively) that consequently has a lower spatial accuracy. VMS was only available for the larger vessels >15 m from 2005 onwards and was therefore judged insufficient for a comparison with the track plot data, as the majority of vessels fishing in the area did not carry VMS for the relevant period.

Video transects to sample fauna and substratum. Sampling was conducted using an underwater video system mounted on a sled with the camera positioned facing the seabed at a $45^{\circ}$ angle from a horizontal position. At each sampling site, a video sled was towed at a speed between 0.5 and 0.8 knots $\left(0.26\right.$ and $\left.0.41 \mathrm{~m} \mathrm{~s}^{-1}\right)$ for $\sim 10 \mathrm{~min}$ in a more or less straight line along the seabed. The start and end positions of each tow were recorded from the moment the sledge had reached the sea floor to the point when the sledge lifted off the seabed during hauling. The field of view of the video image covered approximately $409 \times 304 \mathrm{~mm}$ and was recorded to DVD. Video transects of the second survey were positioned as close as possible to the original transects of the first survey. However, due to the wind and tide it was not possible to position the ship and sledge precisely over the same transect, and the locations of tows differed between the 2 surveys by $\sim 50$ to $200 \mathrm{~m}$.

Abundances and sizes of 9 epibenthic species were recorded from video tow samples, 5 species of emergent sessile epifauna, the pink sea fan Eunicella verrucosa, the calcareous bryozoan Pentapora fascialis (ross coral), the erect sponge Axinella dissimilis, the soft coral Alcyonium digitatum (dead men's fingers) and the tunicate Phallusia mammillata, and 4 epibenthic species of commercial interest, the scallops Pecten maximus (king scallop) and Aequipecten opercularis (queen scallop), and the crabs Cancer pagurus (edible crab) and Maja squinado (spider crab). Abundance data was standardized to tow length. The average size of a species was calculated for each individual tow. Size measurements were conducted from freezeframed video images, and only organisms that were at the same level plane within the field of view of the camera (i.e. same distance from camera) and that had the same orientation were selected for size measurements. This approach increased the comparability of our measurements. Thus for example, organisms in the background or at an extreme angle to the camera were not selected for measurement. Organisms that were only partly seen within frames were included by estimating their size taking advantage of their bilateral symmetry. A bias towards small individuals can be excluded as the size of organisms studied was well inside the frame size of the video. Pink sea fans and spider crabs were the largest organism recorded and in all cases their size could be either measured or estimated. A scaled reference image, including objects of known size, was used to convert measurements to a metric scale. Both height and width were measured for emergent epifauna, while for scallops, the 2 widest points of the shell on the horizontal plane where measured. For the 2 crab species, the carapace width and horizontal height were measured. A relative measure of size was calculated for each species by multiplying width and height (surface area, $\mathrm{cm}^{2}$ ). In addition to recording species abundance, the occurrence of individuals over specific substratum types was recorded to determine associations with different substrata. A total of 6 different substratum categories were recorded through visual classification: (1) sand (0.25 to $2 \mathrm{~mm})$, (2) gravel (>2 to $64 \mathrm{~mm}$ ), (3) gravel with cobbles ( $>64$ to $256 \mathrm{~mm})$, (4) sand and cobbles, (5) gravel with cobbles and boulders (>256 to $4096 \mathrm{~mm}$ ), and (6) rocky reef. Rocky reef was defined as substratum composed of bedrock, large boulders or boulder fields.

Statistical analysis. Assessing differences in substratum type and past fishing effort among treatment groups: The recorded substratum types of replicate treatments were compared using multivariate statistics and by using the PERMANOVA routine (Anderson 2001) in PRIMER v.6. The analysis was based on a Bray-Curtis similarity matrix calculated from the percentage cover of the different substratum types. The PERMANOVA test performed was a full 3-way factorial design with interaction terms (Anderson et al. 2008). The following fixed factors were used: (1) Pro- 
tection, 2 levels; inside 'Closed' and outside of the reserves 'Open', (2) Fishing, 2 levels; 'Fished' and 'Not fished' (mean \pm SD times dredged between 2000 and 2006 within 'Fished' areas $=1.01 \pm 0.48$ and within 'Not fished' areas $0.07 \pm 0.06)$, (3) Time, 2 levels; March and August cruise. Significant effects of treatments were further analyzed with the SIMPER routine of Primer v.6 to determine which habitat types contributed most to the observed differences.

Effects of protection, past fishing events and survey on epifauna abundance: The effect of protection, past fishing events and time on the abundance of sensitive epifaunal species and target species were analyzed within Generalized Linear Models (GLMs) reflecting the factorial design described in the above PERMANOVA analysis on sediment types. The GLM approach is particularly appropriate for count data, as collected by this study, which tends to follow Poisson or negative binomial error distributions (Zuur et al. 2009). Six of the 9 species were analyzed using negative binomial distributions with a log link function after checking for overdispersion under Poisson and negative binomial error distributions (Lindsey 1999). GLMs were performed in R utilizing the MASS package. The models included the length of each video tow as an offset term to standardize count data to tow length (sampling effort). Non-significant interaction terms and factors were sequentially dropped from the full model to attain an optimal model for each species. A precise description of procedures adopted can be found in Zuur et al. (2009). Significance testing of main effects and interactions was conducted by fitting individual terms sequentially to form the optimal model in a hierarchical approach. The contribution of each effect to the explained deviance was tested by the $\chi^{2}$-test ( $\mathrm{p}$-values).

Cancer pagurus, Maja squinado and Phallusia mammillata were generally rare species and had high frequencies of zero values (52 to $85 \%$ ) and thus did not conform to Poisson or negative binomial error distributions. The data was therefore transformed to presence and absence data and analyzed utilizing a model with a binomial error distribution with a logit link function. The same modelling procedures as outlined for the negative binomial distributions (see above) were adopted for these data.

Effects of fishing intensity on size of epifauna: As not all individuals seen within the video footage could be used for size measurements (see 'Video transects to sample fauna and substratum') the availability of size data was limited. To attain a sufficient number of measurements to calculate average sizes per site, data from both cruises was pooled by site. Only sites with 3 or more measurements were considered in the final analysis. Regardless of pooling there were too few measurements to enable a valid comparison for
Axinella dissimilis, Cancer pagurus, Maja squinado and Phallusia mammillata. The relationship between fishing intensity and body size of the observed benthic organisms was explored using least square regressions. Measurements were too sparse for a factorial design including all 3 main factors as performed on the abundance data.

Habitat association of epifauna: We examined habitat associations with the 9 species studied. The analysis aimed to compare the substratum association of Pecten maximus and Aequipecten opercularis (the target species) with those of sensitive emergent epifaunal species in order to evaluate the degree of overlap between target and non-target species in relation to seabed habitat type. Only data from sites that were not fished were used to thereby exclude any confounding effects of fishing activities (this analysis included the sites surveyed within Reserve $C$ ). The occurrence data were converted to percentages and analyzed within a Euclidean distance dissimilarity matrix to determine dissimilarities and conversely similarities in the substratum preference of the studied species.

\section{RESULTS}

\section{Differences in substratum type and fishing effort among treatment groups}

The PERMANOVA analysis showed that there was no significant difference in substratum type composition of video transects conducted inside and outside the reserves nor for sites that were fished and those that were not fished in the past. However, a significant effect was detected for date when sampling occurred $(p<0.05)$. The latter indicated that the 2 surveys differed in the proportions of substratum types sampled. The SIMPER analysis showed that the 2 substratum types that contributed most to this difference were rocky reef cover and sand and cobble cover (cumulative contribution to the dissimilarity $46.9 \%$ ). The percentage of rocky reef surveyed in August (average cover $31.35 \%$ ) was higher compared to that surveyed in March (average cover 27.44\%). Similarly, video transects undertaken in the March survey showed a higher percentage of sand and cobbles (average cover $14.23 \%$ ) compared to August (average cover 19.91\%). These differences, though significant, seem minor (i.e. a difference in rocky reef of $4 \%$ ) and may be a result of slight variations in the position of the sampling transects or of seasonal differences related to sediment transport. It is possible that winter storms covered some sites with sand during the March survey, leading to an overall lower recorded cover of rocky reef. Large extents of rocky reefs are composed of flat bedrock 
that, when covered with a thin veneer of sand, can easily be misclassified. The detected difference in sediment type between the 2 surveys confounded the interpretation of faunal abundance changes related to time. Reported temporal changes need to be evaluated against this background.

\section{Effects of past fishing events, protection and time on epifauna abundance}

The abundance of dead men's fingers Alcyonium digitatum, and ross coral Pentapora fascialis were significantly lower at fished sites (Table 1, Fig. 2) compared to non-fished sites, a trend that was consistent throughout the 2 sampling events (Fig. 2). The abundance of $P$. fascialis and Alcyonium digitatum were 73 and $67 \%$ lower, respectively at fished sites compared to non-fished sites. The presence of the erect sponge Axinella dissimilis was significantly higher at nonfished sites compared to fished sites (Table 1). Its presence at fished sites (occurrence 15\%) was approximately half that of non-fished sites (occurrence $33 \%$ ).

Reserve placement had a significant effect on the abundance of Alcyonium digitatum, Eunicella verrucosa and Pentapora fascialis (Protection; see Table 1, Fig. 2). The abundances of Alcyonium digitatum and E. verrucosa were 3.9 and 3.4 times higher inside compared to outside reserve areas (Fig. 2). The presence of Axinella dissimilis and Maja squinado was significantly higher at sites that lay within the reserves compared to sites outside the reserves (1.9 and 2.2 times, respectively; Table 1, Figs. 2 \& 3). These results indicated that the reserves were not placed randomly but incorporated higher densities of these respective species compared to areas outside the reserves. No significant effect of protection was detected for the 2 scallop spe- cies Aequipecten opercularis, and Pecten maximus and the tunicate Phallusia mammillata (Table 1, Figs. 2 \& 3).

The abundances of the ross coral Pentapora fascialis and the tunicate Phallusia mammillata were significantly higher in August compared to March (Table 1, Fig. 2), as were the occurrences of Axinella dissimilis and Cancer pagurus (2.6 and 3.2 times higher, respectively; Table 1).

None of the 9 species demonstrated a significant interaction between Protection and Time that could have been interpreted as a recovery response. However, significant interactions between Fishing and Time were observed for the abundances of Alcyonium digitatum and Pecten maximus (Table 1). Between March and August, the abundances of both species decreased within areas previously fished while the opposite trend was apparent within non-fished areas (Figs. 2 \& 3).

The queen scallop Aequipecten opercularis did not show a significant response to any of the 3 main explanatory factors (Fishing, Protection and Time) or their interaction terms. Results for this species were therefore not included in Table 1.

\section{Effects of fishing intensity on size of epifauna using regression analysis}

Investigation of the effect of fishing intensity on the size of selected epifauna using least squares regression gave a significant negative response for Alcyonium digitatum (Table 2). The regression slopes of the 2 scallop species Aequipecten opercularis and Pecten maximus, as well as for the ross coral Pentapora fascialis, were negative while the slope of the pink sea fan Eunicella verrucosa did not show any noticeable trend (Table 2).

Table 1. Results of the generalized linear models of abundance of epibenthic species studied, showing the degrees of freedom (df), explained deviance by factor and interaction, and p-values $\left(\chi^{2}\right.$-test). Factors and interactions included for each species represent the optimal model (see 'Materials and methods: Statistical analysis'). See Figs. $2 \& 3$ for full species names. N.b. $=$ negative binomial, Bi. = binomial, ${ }^{*} \mathrm{p} \leq 0.05,{ }^{* *} \mathrm{p} \leq 0.01,{ }^{* * *} \mathrm{p} \leq 0.001$

\begin{tabular}{|c|c|c|c|c|c|c|c|c|c|c|c|c|}
\hline \multirow{2}{*}{ Species } & \multirow{2}{*}{$\begin{array}{c}\text { Null } \\
\text { deviance }\end{array}$} & \multirow[t]{2}{*}{ df } & \multirow{2}{*}{$\begin{array}{l}\text { Residual } \\
\text { deviance }\end{array}$} & \multirow[t]{2}{*}{ df } & \multicolumn{2}{|c|}{ — Fishing — } & \multicolumn{2}{|c|}{ — Protection - } & \multirow{2}{*}{$\begin{array}{l}\text { Time } \\
\text { Deviance }\end{array}$} & \multirow{2}{*}{$p$} & \multicolumn{2}{|c|}{ Time $\times$ fishing } \\
\hline & & & & & Deviance & $\mathrm{p}$ & Deviance & $\mathrm{p}$ & & & Deviance & $\mathrm{p}$ \\
\hline \multicolumn{13}{|l|}{ N.b. model } \\
\hline A. digitatum & 186.1 & (119) & 129.8 & $(115)$ & 20.55 & $<0.001^{* * *}$ & 27.15 & $<0.001^{* * *}$ & 0.54 & 0.461 & 8.06 & $0.004^{* *}$ \\
\hline E. verrucosa & 128.6 & (119) & 119.2 & (118) & & & 9.45 & $0.002^{* *}$ & & & & \\
\hline P. fascialis & 134.6 & (119) & 106.6 & (118) & 13.21 & $<0.001^{* * *}$ & 6.31 & $0.012^{*}$ & 8.5 & $0.003^{* *}$ & & \\
\hline P. mammillata & 135.6 & (119) & 91.1 & (118) & & & & & $44.51<$ & $<0.001^{* * *}$ & & \\
\hline P. maximus & 142.7 & (119) & 132.5 & (116) & 3.62 & 0.057 & & & 2.22 & 0.136 & 4.36 & $0.036^{*}$ \\
\hline \multicolumn{13}{|l|}{ Bi. model } \\
\hline A. dissimilis & 135.2 & (119) & 113.9 & $(116)$ & 5.39 & $0.020^{* *}$ & 5.19 & $0.023^{* *}$ & 10.64 & $0.001^{* *}$ & & \\
\hline C. pagurus & 101.9 & (119) & 94.2 & (118) & & & & & 7.69 & $0.005^{* *}$ & & \\
\hline M. squinado & 132.7 & (119) & 125.5 & (118) & & & 7.17 & $0.007^{* *}$ & & & & \\
\hline
\end{tabular}



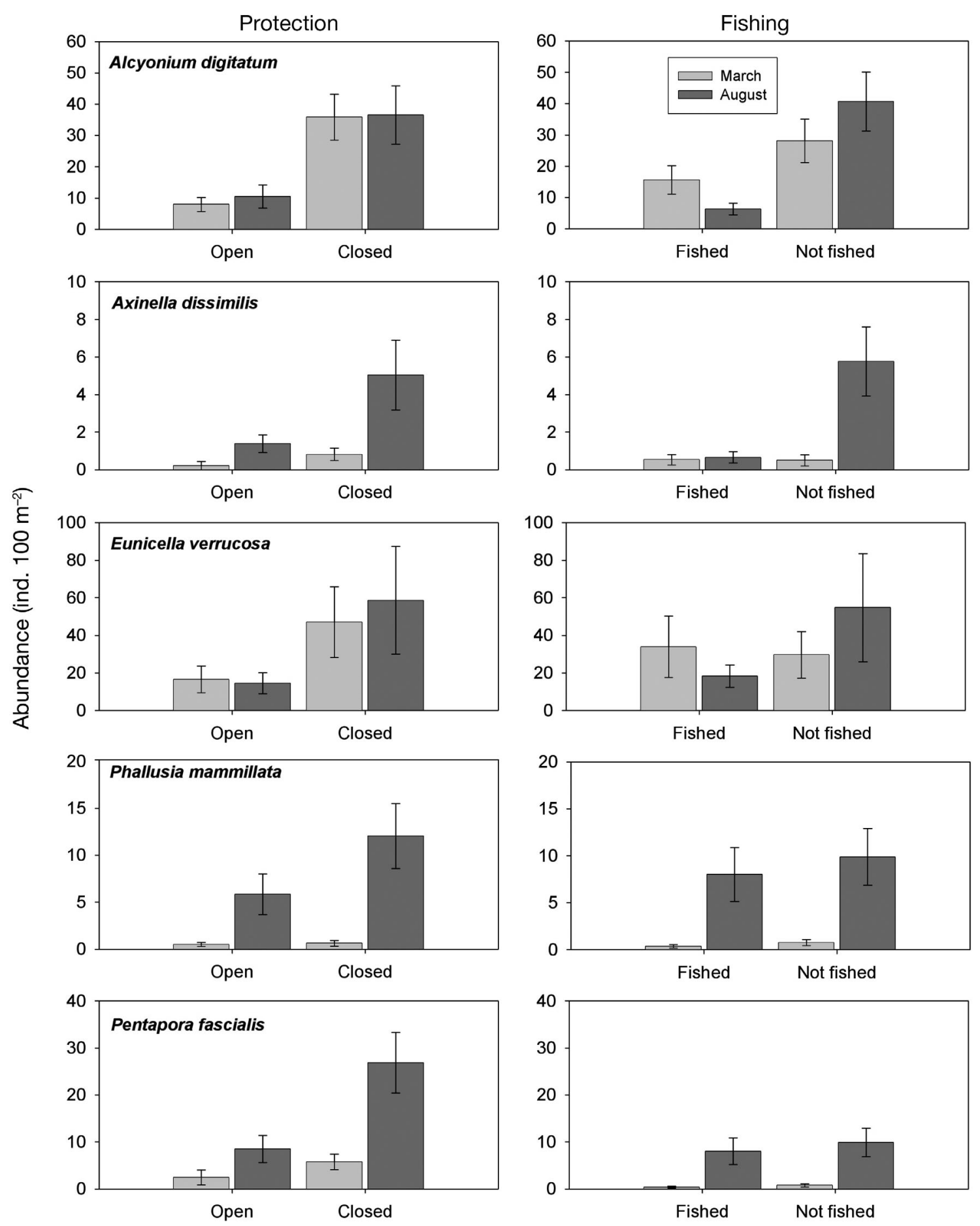

Fig. 2. Abundance $( \pm \mathrm{SE})$ of selected emergent epifauna at sites outside (Open) and inside (Closed) the reserves and at sites fished in the past (Fished) and unfished (Not fished). Surveys were conducted in March (light grey) and August (dark grey) 2007.

Graphs do not reflect the design of the ANOVA analysis

\section{Habitat association of epifauna}

The percentage occurrence data of individuals found over specific substratum types showed that substratum associations differed considerably among species
(Fig. 4). The dissimilarity matrix demonstrated that the target species Pecten maximus and Aequipecten opercularis occurred over very different substratum types compared to Eunicella verrucosa. Both target species had dissimilarities of 73 and $91 \%$ respectively in rela- 

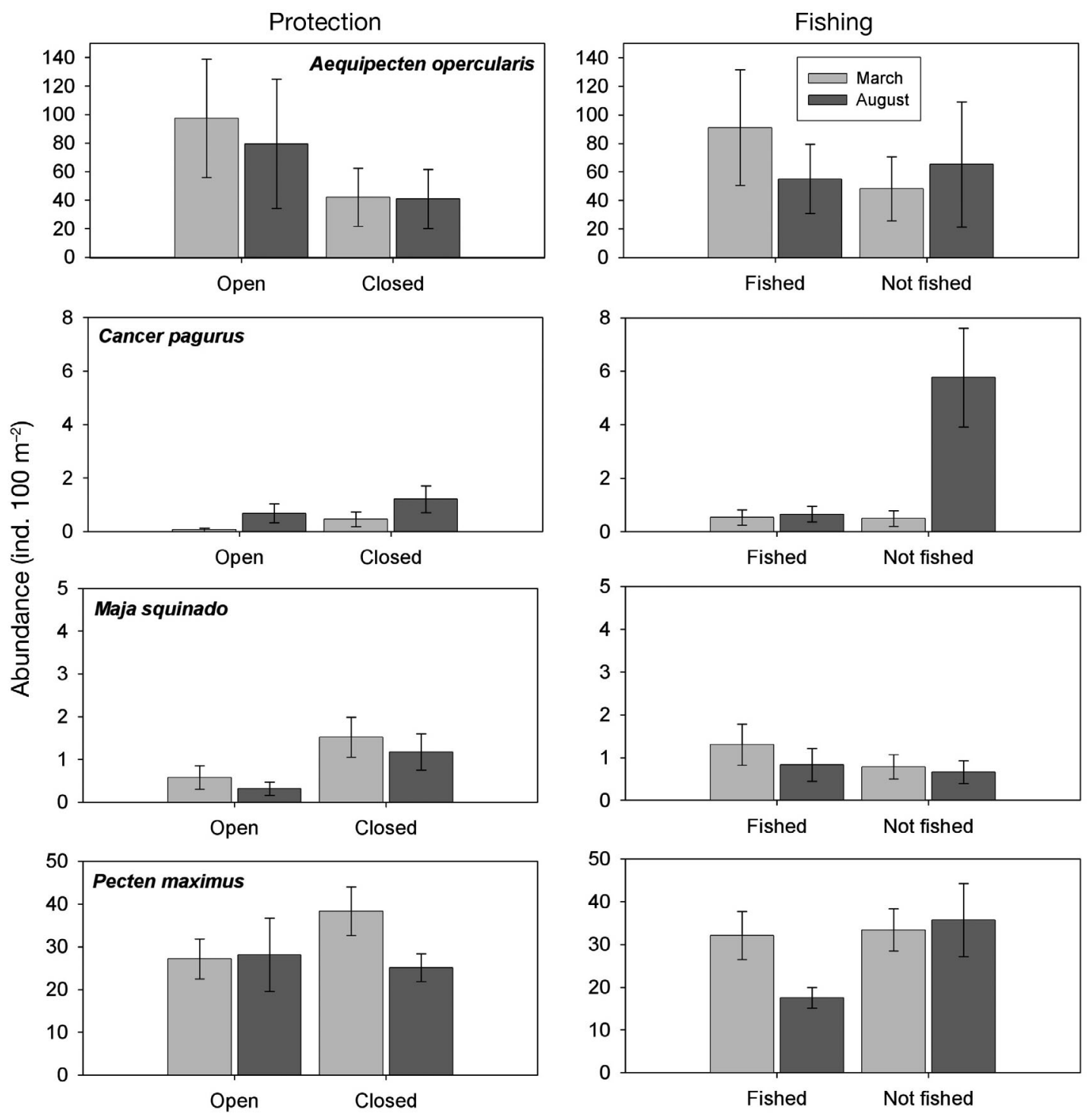

Fig. 3. Abundance $( \pm \mathrm{SE})$ of commercial target species in the present study. Details as in Fig. 2

Table 2. Least square linear regressions of relative fishing effort and the size of epibenthic species. Significant results $(p<0.01)$ are highlighted in bold. See Figs. $2 \& 3$ for full species names

\begin{tabular}{|lccrccc|}
\hline Species & $\mathrm{R}^{2}$ & Intercept & Slope & $\mathrm{df}$ & $F$ & $\mathrm{p}$ \\
\hline A. digitatum & 0.24 & 1.17 & -0.31 & 1,25 & 7.95 & $\mathbf{0 . 0 0 9}$ \\
A. opercularis & 0.15 & 1.36 & -0.17 & 1,19 & 3.43 & 0.079 \\
E. verrucosa & 0.01 & 1.58 & 0.01 & 1,23 & 0.01 & 0.968 \\
P. fascialis & 0.09 & 2.07 & -0.16 & 1,16 & 1.67 & 0.214 \\
P. maximus & 0.05 & 1.64 & -0.31 & 1,52 & 3.07 & 0.086 \\
\hline
\end{tabular}

tion to the substratum associated with E. verrucosa (Table 3). E. verrucosa occurred predominantly over rocky reef while the dominant substratum type for $P$. maximus was sand with cobbles, and sand for A. opercularis (Fig. 4). Alcyonium digitatum and E. verrucosa were associated with similar substrata (Fig. 4). The remaining species all showed a greater resemblance in their proportional occurrence over substratum types to $P$. maximus (Table 3 ). In contrast, A. opercularis had dissimilarities of more than $65 \%$ for these species, which indicated that it occupied a very different set of substratum types than all other species examined in this study.

\section{DISCUSSION}

\section{Effects of fishing on the reef fauna}

Within the present study, we investigated the effects of an active scallop fleet on temperate reef epifauna. Scallop dredging had a detectable effect on the abun- 


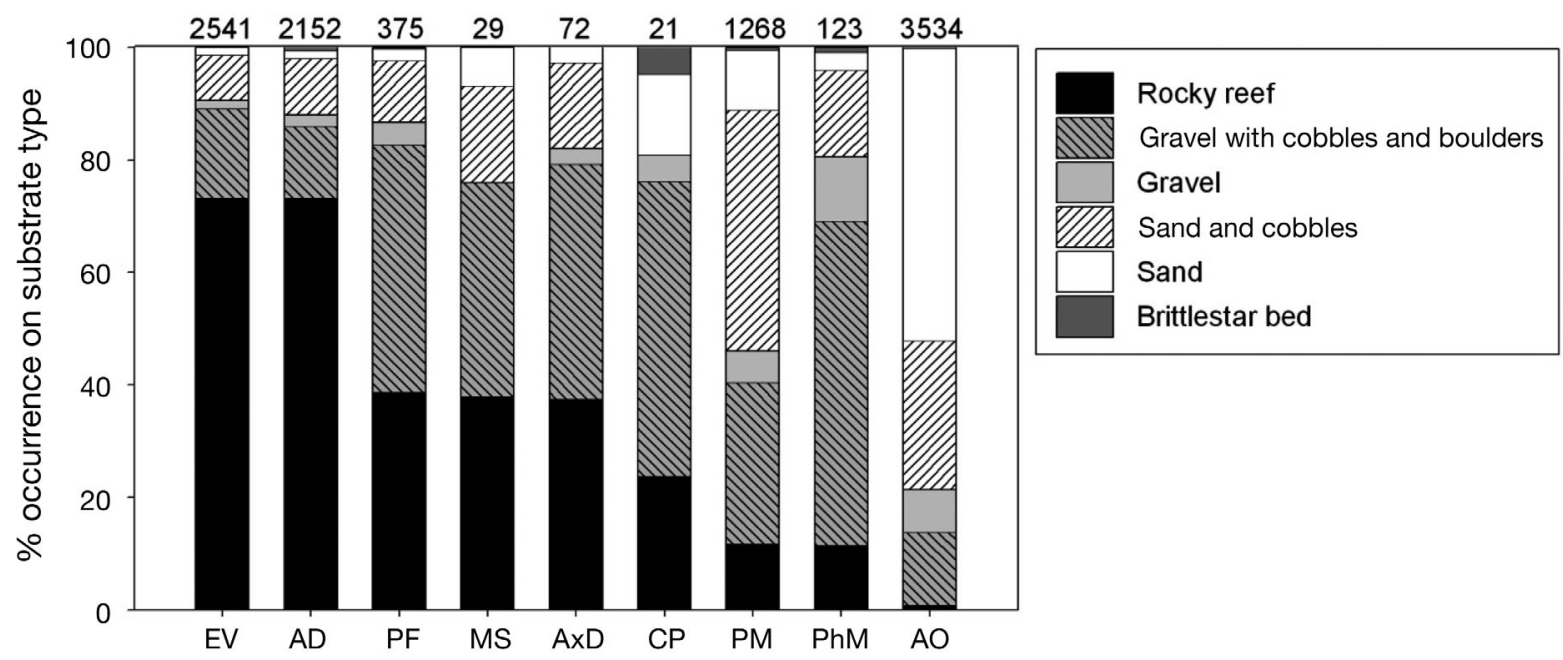

Fig. 4. Percentage occurrence of individuals of studied species over different substratum types at sites that were unfished. Numbers above species columns indicate the number of individuals observed. EV = Eunicella verrucosa, $\mathrm{AD}=$ Alcyonium digitatum, $\mathrm{PF}=$ Pentapora fascialis, $\mathrm{MS}=$ Maja squinado, $\mathrm{AxD}=$ Axinella dissimilis, $\mathrm{CP}=$ Cancer pagurus, $\mathrm{PM}=$ Pecten maximus, $\mathrm{PhM}=$ Phallusia mammillata and $\mathrm{AO}=$ Aequipecten opercularis)

Table 3. Percentage dissimilarity of species substratum associations. Target species of the dredge fishery highlighted by grey shading. See Fig. 4 for abbreviations of species names

\begin{tabular}{|lrrrrrrrr|}
\hline & PM & PF & PhM & MS & EV & CP & AxD & AO \\
\hline AD & 72 & 47 & 77 & 44 & 4 & 66 & 46 & 90 \\
AO & 48 & 72 & 68 & 65 & 91 & 65 & 69 & \\
AxD & 41 & 5 & 32 & 7 & 45 & 26 & & \\
CP & 51 & 24 & 25 & 28 & 64 & & & \\
EV & 73 & 45 & 76 & 43 & & & & \\
MS & 38 & 11 & 35 & & & & & \\
PhM & 41 & 32 & & & & & & \\
PF & 45 & & & & & & & \\
\hline
\end{tabular}

dance of 3 out of 9 of the species studied. The abundance of ross coral Pentapora fascialis and dead men's fingers Alcyonium digitatum were 73 and $67 \%$ lower at fished sites, respectively. Similarly, the presence of Axinella dissimilis (erect sponge) was 54\% lower at fished sites compared to unfished sites. Furthermore, there was evidence of the negative effects of fishing on the body size of individual colonies of A. digitatum. The reductions in the abundance, presence and size of benthic fauna in relation to scallop dredging largely concur with the findings of other studies conducted on biogenic/gravel habitats (e.g. Collie et al. 1997, Hill et al. 1999, Kaiser et al. 2000, Kenchington et al. 2007). In a meta-analysis of fishing impacts, Kaiser et al. (2006) showed that a single disturbance event from scallop dredging caused a reduction in the abundance of taxa of $56 \%$ in gravel habitats, while biogenic habitats showed a reduction of $96 \%$. However, it should be noted that some species within the present study did not show significant responses to fishing. The abun- dance of all 9 species combined was on average $29 \%$ lower in fished sites compared to non-fished sites.

It was not possible to precisely quantify the frequency of disturbance experienced by fished sites within this study as only $12 \%$ of the local fishing fleet provided fishing effort data. Average fishing activity over fished sites was $1.01 \pm 0.48$ (mean \pm SD) times trawled within a $7 \mathrm{yr}$ period, which equated to 0.14 times trawled per year. Assuming that the dredging effort from available track plots was representative for the remaining fleet, the overall effort may be extrapolated to provide a rough estimate of fishing intensity at fished sites. Based on this assumption, the fished sites were estimated to have been dredged on average 1.2 times per year. This level of fishing impact approximates to the once per annum disturbance frequency thought to be representative for most fished systems (Dinmore \& Jennings 2004) and the single impact events described within the meta-analysis by Kaiser et al. (2006).

For the fishing intensities estimated in this study, no effect of dredging on the abundance and size of the pink sea fan Eunicella verrucosa was detected. This species is of primary conservation concern within UK waters and is assumed to be highly sensitive to physical disturbance similar to other emergent epifauna (Jennings \& Kaiser 1998). The lack of a clear response to fishing disturbance was contrary to expectations. No effect was apparent despite the high sampling effort (n $=120$ ) of the present study and the relatively common occurrence of E. verrucosa within the sampling area. A power analysis of the sampling design showed that the minimum effect size for the factor Fishing was 0.25 at the conventional $\alpha$-level of 0.8 (80\% chance of detect- 
ing a difference if it was present) and $\beta$-level of 0.05 . Considering the pooled standard deviations of fished and unfished sites $( \pm 94.5 \mathrm{SD})$, the sampling design should have been able to detect a minimum average difference of 23.5 ind. $100 \mathrm{~m}^{-2}$ or a reduction of $55 \%$ from unfished to fished sites. This result supported the notion that the sampling design was sensitive enough to reliably detect broad scale changes on the magnitude detected for some of the other selected species. It therefore has to be concluded that $E$. verrucosa was less susceptible to fishing than previously assumed within the context of this study. E. verrucosa was found to be mainly associated with rocky reef substratum composed of bedrock or larger sized boulders representing topographically complex habitats. It can be expected that the impact of scallop fishing gear is more severe on flat areas of seabed where the gear would remain in continuous contact with the seabed. In contrast, within topographically more complex substrata, i.e. composed of large boulders or bedrock slabs, the impact of the scallop gear may be reduced as contact with the seafloor will be erratic, with scallop dredges bouncing over boulders and crevices on the seafloor. This will lead to a proportion of unimpacted areas (e.g. behind boulders or within crevices) within the swath of a scallop dredge tow. Similarly, the flexibility of E. verrucosa colonies may contribute to make this species less susceptible to dredge damage than previously assumed. E. verrucosa have been shown to bend when in contact with lobster pots and to recover their posture once the pots are lifted (Eno et. al 2001). The association of this species with topographically more complex substratum types together with the flexibility of its body may provide a possible explanation for why no fishing effects could be detected for this species at low fishing intensities. Higher intensities of scallop dredging may however, over long periods lead to the erosion of complex habitats, ultimately removing refuge spaces and thus the associated fauna. For these reasons, our study emphasizes the importance of the environmental context in which fishing activities occur.

\section{Placement of initial reserves}

The main management objective in the placement of the 4 voluntary reserves in Lyme Bay was to protect populations of the pink sea fan Eunicella verrucosa from the impacts of scallop dredging. The reserve boundaries agreed with local fishermen were based on semi-quantitative data collated from various sources over several years, including local dive surveys and fishermen's knowledge. While these data represented the best available knowledge at the time, uncertainties remained as to whether the placement of the reserves would meet the conservation objectives, particularly given the biased sampling design of previous surveys. The results of the present study support the perception that the placement of the reserves would have met the initial conservation objectives. Not only was the abundance of E. verrucosa 3.4 times higher within reserve boundaries but also other sensitive species such as dead men's fingers Alcyonium digitatum and ross coral Pentapora fascialis had higher densities within the reserve boundaries compared to the areas outside the reserves (3.9 and 2.9 times higher, respectively). Similarly, the presence of the erect sponge Axinella dissimilis and the spider crab Maja squinado were significantly higher within the reserves (2.2 and 1.9 times higher, respectively). Densities of the target species Pecten maximus were almost equal in areas outside and within the reserves. As a result, the reserves could have served as an effective refuge for scallop biomass and subsequent reproductive output in the event of scallop depletion in surrounding areas that were open to fishing.

The success of MPAs in achieving their management objectives has been linked to their correct placement and to stakeholder support (Gleason et al. 2010), while their failure has been blamed on designating areas of convenience with the least impact on stakeholders (i.e. fishermen) rather than on sound scientific knowledge (Agardy et al. 2003, Roberts et al. 2003). Within the context of the present study, the 4 initial reserves had stakeholder support and did protect high densities of sensitive species. Despite these findings, in August 2008 the UK Fisheries Minister (after a process of public consultation) took the decision to close a far larger part of Lyme Bay to scallop dredging that incorporated the entire reef system including the 4 initial reserves. The reasoning behind this larger closure was a change in the management objectives which now focuses on not only a single species, but on the protection of the entire reef structure and its biodiversity (Rees et al. 2010). This change in management objectives was not well publicized and consequently led to a severe loss of trust between the UK fishing industry and Government.

\section{Signs of recovery}

The comparison of data collected in March and August 2007 demonstrated seasonal differences between the 2 sampling events with the abundance of most species generally higher in August compared to March. However, there was no significant difference in the occurrence or abundance of epibenthic species within the reserves compared to areas that remained open to fishing across the 2 sampling events. Thus, no 
clear evidence of recovery could be detected 12 mo after the exclusion of scallop dredging. Studies that have reviewed the effects of MPAs indicate that signs of recovery with respect to abundance and biomass may be evident after 1 to $3 \mathrm{yr}$ from the time of their implementation (Halpern \& Warner 2002, Micheli et al. 2004). It should be noted that recovery time is very much context dependent, with respect to the species in question, their life history and the general design of the MPA, i.e. size, connectivity, history of anthropogenic disturbance etc., and thus may take longer than suggested by averaging past observations (Halpern \& Warner 2002).

\section{CONCLUSION}

This study demonstrated that relatively low fishing intensities of scallop dredging can have significant negative effects on temperate reef fauna of a magnitude similar to that reported for gravel and biogenic reefs. Nevertheless, the lack of a uniform response to dredging, in particular the pink sea fan Eunicella verrucosa, demonstrated that not all species are uniformly affected by this activity. It is likely that scallop dredges fish inefficiently when used over topographically more complex areas of the reef, allowing species with a high affinity to these areas to maintain relatively stable populations levels at low fishing intensities. The analysis of substratum associations showed that the 2 scallop species were associated with considerably different substratum types compared to E. verrucosa. This lack of habitat overlap demonstrated that there is a potential for conflict resolution between fishermen and conservation interests. Knowledge of the precise location and extent of habitats could help to devise spatial management plans that would enable fishers to pursue their livelihood while minimizing negative impacts on species of conservation importance.

Acknowledgements. This study was funded by the Natural Environmental Research Council of the UK (NERC) NE/ E011268/1. We thank the South Western Inshore Fishermen's Association (SWIFA) for the provision of track plot data and the Department for Environment, Food and Rural Affairs of the UK (DEFRA) for the provision of overflight data. The officers and crew of the RV 'Prince Madog', R. Gibbs, I. Rees, M. Galanidi, A. Ruiz Frau, L. Murray, A. Queirós, G. Johnson, K. Bohn, J. Gascoigne, V. Prieto, A. Lawrence, M. McHugh, D. Ward and A. Rouyer are thanked for their help in collecting and processing of samples.

\section{LITERATURE CITED}

Abernethy KE, Trebilcock P, Kebede B, Allison EH, Dulvy NK (2010) Fuelling the decline in UK fishing communities? ICES J Mar Sci 67:1076-1085
Agardy T, Bridgewater P, Crosby MP, Day J and others (2003) Dangerous targets? Unresolved issues and ideological clashes around marine protected areas. Aquat Conserv Mar Freshw Ecosyst 13:353-367

Anderson MJ (2001) A new method for non-parametric multivariate analysis of variance. Austral Ecol 26:32-46

Anderson MJ, Gorley RN, Clarke KR (2008) PERMANOVA+ for PRIMER: guide to software and statistical methods. PRIMER-E, Plymouth

Blyth RE, Kaiser MJ, Edwards-Jones G, Hart PJB (2004) Implications of a zoned fishery management system for marine benthic communities. J Appl Ecol 41:951-961

Collie JS, Escanero GA, Valentine PC (1997) Effects of bottom fishing on the benthic megafauna of Georges Bank. Mar Ecol Prog Ser 155:159-172

> Dernie KM, Kaiser MJ, Warwick RM (2003) Recovery of benthic communities following physical disturbance: an empirical test of predictions. J Anim Ecol 72:1043-1056

Dinmore TA, Duplisea DE, Rackham BD, Maxwell DL, Jennings S (2003) Impact of a large-scale area closure on patterns of fishing disturbance and the consequences for benthic communities. ICES J Mar Sci 60:371-380

> Eno NC, MacDonald DS, Kinnear JAM, Amos SC and others (2001) Effects of crustacean traps on benthic fauna. ICES J Mar Sci 58:11-20

Gleason M, McCreary S, Miller-Henson M, Ugoretz J and others (2010) Science-based and stakeholder-driven marine protected area network planning: a successful case study from north central California. Ocean Coast Manage 53:52-68

Guijarro Garcia E, Ragnarsson SA, Eiriksson H (2006) Effects of scallop dredging on macrobenthic communities in west Iceland. ICES J Mar Sci 63:434-443

> Hall-Spencer JM, Moore PG (2000) Scallop dredging has profound, long-term impacts on maerl habitats. ICES J Mar Sci 57:1407-1415

Halpern BS, Warner RR (2002) Marine reserves have rapid and lasting effects. Ecol Lett 5:361-366

Hill AS, Veale LO, Pennington D, Whyte SG, Brand AR, Hartnoll RG (1999) Changes in Irish Sea benthos: possible effects of 40 years of dredging. Estuar Coast Shelf Sci 48:739-750

Jenkins SR, Beukers-Stewart BD, Brand AR (2001) Impact of scallop dredging on benthic megafauna: a comparison of damage levels in captured and non-captured organisms. Mar Ecol Prog Ser 215:297-301

Jennings S, Kaiser MJ (1998) The effects of fishing on marine ecosystems. Adv Mar Biol 34:201-352

Kaiser MJ, Hill AS, Ramsay K, Spencer K and others (1996) Benthic disturbance by fishing gear in the Irish Sea: a comparison of beam trawling and scallop dredging. Aquat Conserv Mar Freshw Ecosyst 6:269-285

Kaiser MJ, Ramsay K, Richardson CA, Spence FE, Brand AR (2000) Chronic fishing disturbance has changed shelf sea benthic community structure. J Anim Ecol 69:494-503

Kaiser MJ, Clarke KR, Hinz H, Austen MCV, Somerfield PJ, Karakassis I (2006) Global analysis and prediction of the response of benthic biota to fishing. Mar Ecol Prog Ser 311:1-14

Kenchington EL, Kenchington TJ, Henry L, Fuller S, Gonzalez P (2007) Multi-decadal changes in the megabenthos of the Bay of Fundy: the effects of fishing. J Sea Res 58: 220-240

> Lindsey JK (1999) On the use of corrections for overdispersion. J R Stat Soc Ser C Appl Stat 48:553-561

Marine Management Organisation (2009) UK sea fisheries statistics 2009. Marine Management Organisation, London 
Micheli F, Halpern BS, Botsford LW, Warner RR (2004) Trajectories and correlates of community change in no-take marine reserves. Ecol Appl 14:1709-1723

Natural England (2010) Inshore special area of conservation (SAC): Lyme Bay and Torbay, SAC selection assessment document, Version 2.5. Natural England, Sheffield

Pauly D, Christensen V, Dalsgaard J, Froese R, Torres F (1998) Fishing down marine food webs. Science 279: 860-863

Rees SE, Attrill MJ, Austen MC, Mangi SC, Richards JP, Rodwell LD (2010) Is there a win-win scenario for marine nature conservation? A case study of Lyme Bay, England. Ocean Coast Manage 53:135-145

Editorial responsibility: Paul Snelgrove, St. John's, Newfoundland, Canada
Roberts CM, Andelman S, Branch G, Bustamante RH and others (2003) Ecological criteria for evaluating candidate sites for marine reserves. Ecol Appl 13:S199-S214

Shephard S, Beukers-Stewart B, Hiddink JG, Brand AR, Kaiser MJ (2010) Strengthening recruitment of exploited scallops Pecten maximus with ocean warming. Mar Biol 157:91-97

Shumway SE, Parsons JGJ (2006) Scallops: biology, ecology and aquaculture, Vol 35. Elsevier Science, Oxford

Zuur AF, Ieno EN, Neil J, Walker NJ, Saveliev AA, Smith GM (2009) Mixed effects models and extensions in ecology with R, 1st edn. Springer Science and Business Media, New York, NY

Submitted: November 8, 2010; Accepted: April 7, 2011 Proofs received from author(s): June 10, 2011 